\title{
What Is the Equity-Efficiency Tradeoff When Maintaining Wells in Rural Haiti?
}

\section{Dionissi Aliprantis}

\begin{abstract}
This paper quantitatively compares water infrastructure interventions that prioritize equity with those that prioritize efficiency. The community-based model developed by Haiti Outreach $(\mathrm{HO})$ trains communities to operate and maintain wells and has clear efficiency gains over the status quo aid model in Haiti that gives communities wells: HO's wells were 8.7 percentage points more likely to be functioning after one year than similarly-constructed wells managed under the status quo model. Because HO's model includes user fees, which raise concerns about equity, I quantify the equity-efficiency tradeoff posed by community-based and aid interventions by determining the preferences of a social planner indifferent between these types of water infrastructure interventions. Since HO's user fees are only 0.6 percent of median income in rural Haiti, under most specifications the efficiency gains of the community-based model outweigh the equity concerns addressed by the aid model.
\end{abstract}

JEL classification: H10, H41, O13, O22, Q25, Q56

Key words: Community-based water intervention, Haiti, Haiti Outreach, user fee, well maintenance

Haiti, the first free country in the Western hemisphere, is widely regarded as a "republic of NGOs," competing with India for the highest rate of Non-Governmental Organizations (NGOs) per capita in the world (Collier 2010; Clinton 2010). ${ }^{1}$ The proliferation of NGOs in Haiti is indicative of the weakness of its public sector. One World Bank report estimates that NGOs provide 70 percent of health care in Haiti's

Dionissi Aliprantis is a research associate at the Interuniversity Institute for Research and Development (INURED), Portau-Prince, Haiti, and a research economist at the Federal Reserve Bank of Cleveland; his e-mail address is dionissi.aliprantis@ gmail.com. This work was supported by the Inter-American Development Bank's Office of Evaluation and Oversight [grant number A0009778-001] while the author was on unpaid leave from the Federal Reserve Bank of Cleveland. A previous version of this paper circulated under the title "Community-Based Well Maintenance in Rural Haiti." I thank Neil Van Dine, Dale Snyder, Dimitri Papadimitriou, Mark Schweitzer, Ben Craig, Ellis Tallman, Nelly Soupe, Fabienne Doucet, Herns Marcelin, Marc Prou, Chuck Dietzen, Paul Park, Eddie Kubek, Rich Gosser, Richard Sévère, Ed Smith, Alex Eble, Anna Crespo, and several anonymous referees. The opinions expressed here are those of the author alone and do not represent the views of INURED, the IDB, Haiti Outreach, the Federal Reserve Bank of Cleveland, or the Board of Governors of the Federal Reserve System. A supplemental appendix to this article is available at The World Bank Economic Review website.

1 When considering the rate of NGOs per capita it must be noted that estimates of the number of NGOs working in Haiti or in any other country often differ by orders of magnitude (Schwartz (2010b), Schwartz (2010c)). See Trouillot (1990) (p 44) for documentation that Haiti was the first country in the Western hemisphere both to gain independence and to abolish slavery. 
rural areas, and that public schools are able to accommodate only 10 percent of school-age children (World Bank 2006). All of the US Agency for International Development's (USAID's) funding for Haiti during the fiscal year 2007-2008, a sum of \$300 million, was allocated to foreign NGOs (USIP 2010).

The prominent role of NGOs in Haiti raises at least two natural questions about their work. One is: How can NGOs integrate their efforts into those of the public sector when the state is weak? Private donations and official pledges for reconstruction surpassed \$14 billion by June 2010 (HRF 2010; Ramachandran and Walz 2012), and there is a lively debate about whether disbursing such money through NGOs gives excessive power to donors, rather than the Haitian government, for setting policy (Schuller 2007). Consider that after a 2009 donors' conference “donors provided only $\$ 40$ to $\$ 70$ million of the more than $\$ 350$ million in pledges and continued to direct assistance through NGOs rather than the government" (USIP 2010). Similarly, of the \$194 million in post-earthquake contracts funded by the US government until April 2011, only 2.5 percent were awarded to Haitian firms (Dupuy 2010; CEPR 2011). Outsiders must consider the long-term implications of their actions when making decisions that are typically made, or at least regulated, by the government (Schwartz 2010a; Schuller 2012; Katz 2013).

Another question, perhaps even more basic, is: How can NGOs most effectively perform their own work? The provision of safe water in rural areas is a major focus of NGO work in Haiti, with the cost of building a nationwide water and sanitation infrastructure estimated to be \$1.6 billion (Katz 2014). This work is being conducted against the backdrop of a shifting consensus on whether safe water interventions should focus on community-level water infrastructure, home water treatments, or sanitation (Parker and Skytta 2000; Waddington and Snilstveit 2009). Within water infrastructure interventions there is evidence comparing community-based interventions with government supervision (Zwane and Kremer 2007; Ahuja et al. 2010), but the weak public sector in Haiti makes the more relevant comparison there between community-based interventions training communities to manage wells and aid interventions simply constructing wells.

This paper quantitatively compares the efficiency gains of a community-based approach to providing water in rural Haiti with the equity concerns addressed by the aid status quo. To be precise, this paper answers the following question: If a social planner with a fixed budget and preferences over demographic characteristics wants to transform their money into water-person-years in rural Haiti, which intervention should they choose between a community-based intervention that is more efficient and an aid intervention that is more equitable? By characterizing the preferences of an indifferent social planner, I am able to answer this question for social planners with stronger or weaker preferences for providing water-person-years to particular households.

The community-based model evaluated in this paper was developed by Haiti Outreach (HO) and is distinguished by a program training communities to manage the operations and maintenance of their wells. I first show that HO's model does indeed increase efficiency: HO's wells were 8.7 percentage points more likely to be functioning after one year than similarly-constructed wells managed under the status quo model. The control group of aid wells used in this comparison was created in response to the earthquake in Haiti on January 12, 2010. HO was asked to assess and repair 158 wells by Haiti's National Ministry of Potable Water and Sanitation (DINEPA). ${ }^{2}$ These data allow for an identification strategy in which construction standards were similar across community-based and aid wells, so that differences in past outcomes can be narrowed to differences in operations and maintenance and the composition of complier/never-taker communities.

Because the user fees contributing to this gain in efficiency raise concerns about equity relative to the aid status quo, which is primarily focused on giving wells to communities, I then determine the preferences of a social planner indifferent between these types of water infrastructure interventions. I specify a social planner's objective function to be the sum of the preference-weighted water-person-years (Koestler et al.

2 DINEPA is the Direction Nationale de l'Eau Potable et de l'Assainissement. 
2009) produced by an intervention with a fixed budget. In this analysis I specify the social planner to have preferences for providing water to poor households for normative reasons and because the takeup rate of water and public health interventions has been documented to be highly sensitive to price (Palmer et al. 2004; Kremer and Miguel 2007; Ahuja et al. 2010; Cohen and Dupas 2010). In general, though, the framework can accommodate a social planner who might have preferences for providing water to households with many children who stand to benefit most from clean water (but who may receive little weight in household decisions on water [Ahuja et al. 2010]), with either high or low levels of educational attainment (Jalan and Ravallion 2003), that are located far away from alternative water sources (Kremer et al. 2011), or with other characteristics (including being in a complier or nevertaker community).

Under conservative assumptions about the effects of user fees on access, I find that social planners who care about the poor, and not just the very poorest, prefer community-based interventions to aid interventions. For a planner to prefer the aid intervention to the community-based intervention in rural Haiti, it would be required that they prefer to provide water to one household at the lowest income level rather than three median-income households. ${ }^{3}$ The efficiency gains of the community-based model outweigh the equity concerns addressed by the aid model under most "reasonable" preferences because HO's user fees are only 0.6 percent of median income in rural Haiti.

A general implication of these results for the literature is that community-based property rights arrangements can allow for an alternative between open access and privatization, which is especially relevant to situations without the presence of a strong public sector. ${ }^{4}$ Well owners in HO's communitybased model are communities that, while able to restrict access, are more accurately described as water-person-years-maximizing than profit-maximizing (Kremer et al. 2011). ${ }^{5}$ An implication of these results for Haiti's development is that it is possible to focus on both long-term development and shortterm relief at the same time. HO's community-based model effectively attends to the urgent need in Haiti for safe water, all the while building the capacity of local communities to make and enact collective decisions.

The remainder of the paper is organized as follows: Section I discusses alternative approaches to maintaining water infrastructure in rural areas, including definitions of top-down, community-based, and aid interventions. Section II provides a general framework for quantitatively comparing such interventions based on a social planner's preferences, with a focus in this analysis on the equity-efficiency tradeoff between interventions. Section III describes the community-based management training developed by Haiti Outreach, and section IV introduces the data used in the analysis. Section V discusses how the counterfactuals used in the decision problem are identified, and section VI quantitatively compare HO's community-based intervention and an aid intervention. Section VII concludes.

\section{Water Infrastructure: Maintenance and Access}

There is a broad debate on the most effective interventions to improve access to safe water for the 884 million people who only have access to unimproved water sources (WHO 2008). ${ }^{6}$ Since most of these individuals, 84 percent according to WHO (2008), reside in dispersed rural areas where the expense of constructing piped water systems is prohibitive, safe water interventions have traditionally focused on

3 The median household in rural Haiti has daily per-capita income of 0.93 US dollars (2004 dollars corrected to account for purchasing power parity (PPP)), which is well below the poverty line (Ravallion et al. (2009)).

4 See Ostrom and Gardner (1993) and Ostrom (2014) for discussions of related institutional arrangements.

5 The possibility of privatizing ownership is more relevant for urban centers in Haiti than in rural areas. See Galiani et al. (2005) for related evidence from Argentina.

6 WHO (2008) defines the category improved drinking water sources to include "sources that, by nature of their construction or through active intervention, are protected from outside contamination, particularly faecal matter." 
improving community-level infrastructure. ${ }^{7}$ Obstacles to the consumption of safe water not resolved by improvements to community-level infrastructure, like contamination in transport and storage (Jalan and Ravallion 2003; Brick et al. 2004; Wright et al. 2004) or sanitation and hygiene behaviors (Bennett 2012; Jessoe 2013), have motivated practitioners and researchers to question whether infrastructure improvements should continue to receive priority over alternative interventions (Zwane and Kremer 2007). In fact, the consensus of the 1970s discussed in Parker and Skytta (2000) has reversed, with the current consensus favoring water quality and hygiene interventions over infrastructure improvements (Esrey et al. 1991; Esrey 1996; Waddington and Snilstveit 2009).

Infrastructure maintenance is an important and unresolved issue for judging the relative merits of alternative clean water interventions (Zwane and Kremer 2007; Ahuja et al. 2010). This issue is of central importance because a focus on infrastructure maintenance helps to expand the development projects possible under a fixed budget. For example, it has been estimated that $\$ 12$ billion in maintenance could have prevented $\$ 45$ billion in road reconstruction in Africa during the 1970s and 80s alone (World Bank 1988). ${ }^{8}$

Maintaining water infrastructure has proven to be a formidable challenge, despite recent improvements in the related technology (McKenzie and Ray 2004), with evidence to be found in projects of all scales. ${ }^{9}$ At least one third of public handpumps were likely to be out of order in India at any given moment during the 1990s (UNDP-World Bank 1999). Of the nearly 700 wells constructed in western Kenya between 1982 and 1991, only 57 percent had normal flow when surveyed by Miguel and Gugerty (2005) between 2000 and 2001. And in one poorly performing community in Sri Lanka, Isham and Kähkönen (2002) report that three years after the implementation of an infrastructure intervention, only one of the eight completed projects was still operable, while many others were never even completed.

There are at least three approaches to maintaining wells in rural Haiti about which one might be interested in learning. Parker and Skytta (2000) label the two primary approaches to maintaining wells in rural areas as top-down and community-based. The top-down approach is characterized by a centralized, government utility responsible for infrastructure maintenance. While the capacity of the government in Haiti might be increasing over time, the top-down approach does not currently appear feasible in many areas of rural Haiti.

The community-based approach is characterized by the organization of local water committees to oversee well operations. Under the community-based model local communities fund operations and maintenance $(\mathrm{O} \& \mathrm{M})$ and replacement costs, but construction and hardware are typically subsidized by the government or an NGO. ${ }^{10}$ Reviewing the evidence from World Bank rural water projects, Parker and Skytta (2000) conclude that the strength of committees determines the success of community-based interventions. Strong committees can achieve tremendous success: In Côte d'Ivoire, a nation-wide rural water program establishing community groups to maintain water infrastructure at 13,500 water points decreased the breakdown rate from 50 to 11 percent at one-third the cost of the previous top-down approach (World Bank (1996), p 247). This is consistent with evidence from rural Northern Pakistan that project design to increase community participation in non-technical decisions improves the maintenance

7 For example, 95 percent of the World Bank's rural water and sanitation investments between 1978 and 2003 were allocated to community level interventions such as hand pumps, source water protection, and treatments to community storage facilities (Iyer et al. (2006), deWilde et al. (2008)).

8 See Peterson (2008) for a related discussion of road construction and maintenance in Haiti.

9 See McKenzie and Ray (2004) for a brief history of how this technology (cheap and efficient drilling technology, inexpensive and easily maintained handpumps) was developed by the government of India in partnership with private engineering firms.

10 It is likely not feasible for poor communities to fund construction costs: One study found that less than one-fifth of World Bank water supply and sanitation projects that set out to recover costs either partially or fully have succeeded (World Bank (2010a)). 
of community-level infrastructure (Khwaja (2009)). Isham and Kähkönen (2002) present evidence from India and Sri Lanka in which communities were alternately responsible for either part of construction and all of O\&M costs, only O\&M costs, or no costs, and find that communities responsible for O\&M costs reported the greatest decrease in the incidence of diarrhea, as well as the greatest decrease in collection time and best construction quality.

A third approach to maintaining wells, whose empirical relevance renders it the status quo in Haiti (World Bank 2006), might be labeled aid. In this approach foreign NGOs are responsible for maintaining wells, with varying degrees of consultation with local or national government (Collier 2010; Schwartz 2010a; Schuller 2012). Exemplifying the obstacles with this approach is a recent study of wells built by NGOs in Haiti, which found that only 25 percent had any evidence of a management strategy. Of the half with "well keepers," those responsible for operations and maintenance had no power to repair or run the wells (Glum 2014).

A primary concern for the community-based approach relative to the aid approach is user fees, because there is evidence that user fees can dramatically decrease access in public health interventions. For instance, Kremer and Miguel (2007) find that efforts to replace subsidies with cost-sharing measures in Kenya reduce the take-up of an anti-worming drug by 80 percentage points. And Cohen and Dupas (2010) find that dropping the subsidization of antimalarial insecticide-treated bed nets (ITNs) from 100 to 90 percent led pregnant women in rural Kenya to decrease their uptake of the nets by 60 percentage points! Since the take-up of water quality interventions is also highly sensitive to price (Ahuja et al. 2010), the impact of user fees on access must be given careful consideration.

\section{Equity and Efficiency in a Decision Problem}

The community-based approach to rural water supply is rooted in the view that community members themselves are best positioned to be the primary decision makers, not those trying to help them (Briscoe and de Ferranti 1988; Narayan 1993). While normative considerations of agency and efficiency might support such a view, normative concerns around equity could easily be cited in support of aid interventions in which outsiders are the primary actor. What precisely is the tradeoff when deciding between acting as a facilitator offering technical assistance versus a direct provider? In this section, I present a framework for quantitatively comparing water infrastructure interventions that account for the maintenance and access issues discussed in section I.

Let $Y_{j t}(D)$ be the potential outcome indicating whether well $j$ is operational at time $t$ if exposed to treatment regime $D$ :

$$
Y_{j t}(D) \equiv \begin{cases}1 & \text { if well } j \text { is functional at time } t \\ 0 & \text { otherwise }\end{cases}
$$

Throughout this analysis we are interested in comparing one treatment intervention against one control intervention, and we use a binary indicator variable to distinguish between the two types of interventions:

$$
D_{j} \equiv \begin{cases}1 & \text { if well } j \text { receives the treatment intervention between } t=1 \text { and } t=T \\ 0 & \text { if well } j \text { receives the control intervention between } t=1 \text { and } t=T\end{cases}
$$

Suppose there is a social planner who attaches weight $\delta\left(X_{i j}, E_{i j}\right)$ to providing water to a household with observed and unobserved characteristics $\left(X_{i j}, E_{i j}\right)$, which is discounted relative to $\delta(\tilde{x}, \tilde{e})=1$ for some reference household(s) characterized by $(X, E)=(\tilde{x}, \tilde{e})$. Some examples of characteristics that might be included in $(X, E)$ for a social planner include household income, number of children or elderly household members, educational attainment, urban/rural status, physical location, or the household's 
preference for well water. The social planner's preferences over such characteristics might be motivated by a preference for the poor, the fact that the young children who stand to benefit most from clean water may not receive a lot of weight in household decisions on water (Ahuja et al. 2010), that education may be an important barrier to reaping the benefits of water interventions (Jalan and Ravallion 2003), or that revealed preferences indicate walking time to collect water highly discourages uptake (Kremer et al. 2011).

Let $\omega_{i j}\left(D_{j}, X_{i j}, E_{i j}, F_{i j}, t\right)$ be an indicator for whether household $i$ with observed and unobserved characteristics $\left(X_{i j}, E_{i j}\right)$ has access to the well in community $j$ under treatment $D_{j}$ with user fee $F_{i j}$ at time $t$. Assuming that the social planner has a fixed budget, capable of financing $J_{0}$ and $J_{1}$ wells under $D=0$ and $D=1$, the social planner's problem is to maximize the preference-weighted water-person-years (Koestler et al. 2009) produced by choosing between water interventions:

$$
\max _{D \in\{0,1\}} U(D)=\max _{D \in\{0,1\}} \sum_{t=1}^{T} \sum_{j=1}^{J_{D}} \sum_{i}^{I_{j}} \delta\left(X_{i j}, E_{i j}\right) \omega_{i j}\left(D_{j}, X_{i j}, E_{i j}, F_{i j}, t\right) .
$$

In this analysis we suppose that the only characteristic of a household over which the social planner has preferences is relative income, or income quantile $q \in[0,1]$. Adopting the functional form $\delta: \mathbf{X} \times \mathbf{E} \rightarrow[0,1]$ defined by

$$
\delta(q ; \theta)=(1-q)^{\theta},
$$

income quantiles are discounted relative to the poorest household, with $\delta(\tilde{q}=0 ; \theta)=1$. Preferences are characterized by the parameter $\theta \in[0, \infty)$. Planners who are relatively indifferent to where households provided with access to water are located in the distribution of income have very small $\theta$ 's $(\theta \approx 0)$, while social planners with the strongest preferences for providing access to the very poorest of households have very large $\theta$ 's $(\theta \approx \infty)$.

Assume that income quantiles are measured discretely with $q \in\{0,0.01,0.02, \ldots, 1\}$, and define the expected preference-discounted water years produced by intervention $D$ in a given community to be

$$
\mathbb{E}[W(D) ; \theta] \equiv \sum_{t=1}^{T} \sum_{j=1}^{J_{D}} \frac{1}{J_{D}} \sum_{i}^{I_{j}} \delta\left(q_{i} ; \theta\right) \omega_{i j}\left(D_{j}, q_{i j}, F_{i j}, t\right) .
$$

Together with estimates of the expected total cost of intervention $D, \mathbb{E}[T C(D)]$, estimates of $\mathbb{E}[W(D) ; \theta]$ allow for a comparison between the utilities in the decision equation $1:{ }^{11}$

$$
\mathbb{E}\left[\frac{U(1)}{U(0)} ; \theta\right]=\frac{\mathbb{E}[W(1) ; \theta]}{\mathbb{E}[W(0) ; \theta]} \frac{J_{1}}{J_{0}}=\frac{\mathbb{E}[W(1) ; \theta]}{\mathbb{E}[W(0) ; \theta]} \frac{\mathbb{E}[T C(0)]}{\mathbb{E}[T C(1)]}
$$

If user fees increase the production of water-person-years at the cost of excluding the poorest community members from accessing water, then $\mathbb{E}\left[\frac{U(1)}{U(0)} ; \theta\right]$ will be strictly monotonic in $\theta$. In this case there exists a unique $\theta^{*}$ such that $\mathbb{E}\left[\frac{U(1)}{U(0)} ; \theta^{*}\right]=1$, or alternatively, where a social planner with preferences $\theta^{*}$ is indifferent between interventions:

$$
\mathbb{E}\left[U(1) ; \theta^{*}\right]=\mathbb{E}\left[U(0) ; \theta^{*}\right] .
$$

If we are able to estimate $\theta^{*}$, using $\delta\left(q ; \theta^{*}\right)$, we can characterize the preferences of social planners indifferent between interventions, and therefore, due to the monotonicity of $\mathbb{E}\left[\frac{U(1)}{U(0)} ; \theta\right]$ in $\theta$, also the preferences of social planners who prefer one intervention over the other.

11 The appendix A1, available at https://academic.oup.com/wber, derives the equivalence of the ratios of wells $\left(J_{1}\right.$ and $\left.J_{0}\right)$ and average total costs. 


\section{Haiti Outreach's Community-Based Model}

Haiti Outreach's (HO's) community-based model is focused on organizing communities to make collective decisions and then training community members in management practices so as to make those decisions a reality. A description of HO's model is presented in table 1.

Table 1. Description of a Successful Intervention by Haiti Outreach

Step Description Responsible Party

Community initiates project
1) Request for proposals
HO communicates to local mayors it has secured funding
2) Letter of request
Community responds to offer with written proposal
3) Initial meeting
HO meets with community, describes terms of agreement
$\mathrm{HO}$ and Local Government
Community
4) Agreement enacted
HO Animator
Community and $\mathrm{HO}$

Committee undergoes management training
5) Committee forms
Committee is organized to oversee O\&M of well
6) Conducts census
Determines community boundaries, conduct census
7) Acquires deed
Acquires deed for the land, which becomes property of local government
8) Determines O \& M rules
Sets subscription fee and hours of operation, hires guard, etc.
9) Prepares for construction
Ensures site accessible for $\mathrm{HO}$ truck, finds lodging for workers and equipment
10) Signs contract
Signs legally-binding construction contract with $\mathrm{HO}$

Community and $\mathrm{HO}$

Animator

Committee and $\mathrm{HO}$

Animator

Committee and $\mathrm{HO}$

Animator

Committee and $\mathrm{HO}$

Animator

Committee and $\mathrm{HO}$

Animator

Committee and $\mathrm{HO}$

HO fulfills their side of agreement

11) Construction

Well is drilled/rehabilitated, pump is installed, well house is constructed

12) Inauguration ceremony

Keys to well house are handed over to committee

$\mathrm{HO}$

Committee, HO, Elected Leaders, and Community

Community fulfills their side of agreement

13) Operation

14) Maintenance

15) Upgrade

16) Follow-up

Haiti Outreach exits

17) $\mathrm{HO}$ exits
Committee meets, subscribers pay fees, $\geq 200$ gds ( $\approx \$ 5$ ) deposited monthly into well's account

Committee determines when to use funds for repairs

If sufficient funds are saved, committee may use funds for electric pump, etc.

Inspector meets with committee

$\mathrm{HO}$ ends engagement with community
Committee

Committee

Committee

HO Inspector

Source: Haiti Outreach.

Especially noteworthy about the HO model is that it integrates its efforts into those of the public sector. Not only does HO work through the mayors of the communities it serves, but it also builds the capacity of those communities to make collective decisions and implement them. Because HO's work builds capacity for local governance, DINEPA has endorsed the HO model and is currently involved in an ongoing collaboration with $\mathrm{HO}$ to build 100 wells in the north of Haiti. ${ }^{12}$

12 Additional details on the history of HO and the details of their model can be found in Aliprantis (2013) and Ocwieja et al. (2011). The idiosyncracies of HO's model have grown out of decades of experience working on development projects in Haiti, which according to the water poverty index created by Lawrence et al. (2002) ranks 140 out of 140 countries, and therefore HO's model is likely to be most relevant for countries with similar water needs. Despite these great 
Also noteworthy is that HO plans to leave communities. This step makes HO a model for all organizations working in Haiti, and its significance cannot be overstated: By focusing on building the capacity of communities to manage their own development projects, HO's goal is to leave communities independent of the need for further intervention by outsiders.

There are several reasons one might expect HO's community-based approach to be more effective than alternative interventions. First, the committee structure ensures that wells are handled with care. The existence of a user fee, however small, may make users more careful when using their community's pump. Furthermore, wells are only open during a certain portion of the day, and at all other times the well's shelter ensures that children or animals cannot harm the well. Second, the committee's ability to direct both attention and savings to the well ensures that small problems are repaired before they become big ones, and that big problems are solved if they arise.

Finally, committee oversight of operations and maintenance makes a community's well an excludable good. Members of nearby communities with broken wells might travel to use a community's well if it is open to anyone at any time. Committee oversight ensures that only current subscribers can access the well at predetermined times. It is important to note here that the property rights arrangement in the HO model is somewhere between the communal and private property rights definitions in Kremer et al. (2011). Although the property rights regime in the HO model does not allow for open access, it is not one of profit-maximizing well owners. Well owners are communities that, while able to restrict access, are more accurately described as water-person-years-maximizing.

Project managers, or animators, play a central role in ensuring that committees are established and communities are engaged. Beginning with decisions of who will take the designated positions on the committee, project managers observe each decision made by the committee. Project managers make sure that no individual or group dominates and that all voices are heard during the decision-making process. Many of the first steps asked of communities and their committees by $\mathrm{HO}$ are designed not only to complete a given task but also as a way for $\mathrm{HO}$ project managers to observe if committees are engaged and working well together.

\section{Data}

The Leogane Sample, or Control Group Wells

In order to compare HO's community-based intervention (treatment) with the status quo aid intervention in Haiti (control), we analyze two samples of wells whose construction and functionality both met HO's standards at the same point in time but whose operations and management subsequently differed after construction. The control group wells comprised by the Leogane sample were determined by a "natural experiment" in that Haiti Outreach was asked by the Haitian government to ensure that 158 wells and water points in the Leogane area were functional after the earthquake of January 12, 2010. Haiti Outreach conducted an assessment of these wells from January 26 to 28, 2010, and 45 wells were found to be nonfunctioning. Seven of these wells were not repaired or are no longer operational because they are located above dry ground. HO repaired 21 of the remaining 38 wells found to be in need of service between February 3 and April 13, 2010, and the other 17 were repaired by other emergency groups. Thus all wells in the Leogane sample were judged by HO's standards to be functioning by May 2010, with the timing and location of the earthquake leading to the creation of this control group of wells in Leogane therefore being quasi-randomly determined.

Subsequent data on wells in the Leogane sample were collected by Haiti Outreach, the Japan Emergency NGO (JEN), and the author. The author visited 127 of the 151 wells in this sample (84.1 percent) between April 12 and 14, 2011, using data provided by Haiti Outreach on the Global Positioning System (GPS)

needs in Haiti, development assistance designated for improvements to water infrastructure there has been disrupted in the recent past for political purposes (Varma et al. (2009)). 
coordinates of each well. GPS records were not kept of the wells repaired by HO, but review of HO's records indicates that of the nonfunctioning wells visited by the author in April 2011, none were in the group originally judged nonfunctioning and scheduled for repair by HO. Information on subsequent repairs made to the wells in the Leogane sample were provided by personal communication with staff of JEN.

\section{The Haiti Outreach Sample, or Treatment Group Wells}

The treatment group wells are comprised by an early subsample of $\mathrm{HO}$ wells, with classification into the early and late subsamples based on the date of inauguration of each well. The early subsample is defined as those wells inaugurated in May 2010 or earlier, to ensure a comparable group of wells that were constructed at or before the time at which the Leogane sample was rehabilitated. Unfortunately, the early HO subsample has only 22 wells, and only 20 of these have all variables present. An additional 27 wells are a part of the late HO subsample. These wells were inaugurated after May of 2010 and therefore were not constructed during a time period comparable to the wells in the Leogane sample. However, these wells do provide data on subscription fees and community characteristics.

There are 47 additional wells in the HO sample that are not a part of this analysis because they are either too new or not yet inaugurated, so do not yet have data. HO is conducting management training and construction for these wells in collaboration with Water.org, the Inter-American Development Bank, DINEPA, and V3. Many of these wells are on the island of La Gonave, where wells are deeper and harder to drill than those near HO's headquarters in Pignon, and communities are poorer. To this point communities on La Gonave have been very engaged with the HO model, perhaps as a result of these difficulties. An area for future research will be to see if communities are able to overcome the additional obstacles on La Gonave through increased engagement to produce results similar to those near Pignon.

The majority of data on wells in the Haiti Outreach sample was collected by community members themselves. As discussed in table 1, community members must conduct a census in which they determine the number of people in their community. The committee must also keep monthly records of the subscriber fees collected, condition of the pump/well, assets, and expenses associated with the well. Members of the HO staff provided these data to the author after gathering them from HO's paper records and entering them into an electronic database. Variables in the HO data set include GPS coordinates, the number of community members, the total number of households in the community, number of households ever registered, the monthly subscription fee, the number of households with latrines, and the dates of application, inauguration, and most recent inspection for each well.

\section{Geographic and Demographic Variables}

To augment the data from the Leogane and HO samples, geographic data were downloaded from the Haiti Earthquake Data Portal at Harvard University's Center for Geographic Analysis, with data on rivers and roads coming from the United Nations Stabilization Mission in Haiti (MINUSTAH). Together with the GPS coordinates of each well, the geographic data were used in ArcGIS to construct the following variables for each well: distance to a major road, distance to a minor road, distance to a major river, and distance to a minor river. GPS coordinates were also used to create a variable for each well measuring the distance to the nearest well in the sample for both the Leogane and HO wells.

The empirical analysis also uses demographic data from the fourth general census of Haiti conducted by the Haitian Institute of Statistics and Information (IHSI) in 2003, and from the Haiti Youth Survey 2009 (Lunde 2009, 2010) conducted by Fafo with help from the IHSI.

\section{Descriptive Statistics}

Figure 1a is a map produced by USAID showing how areas in Haiti were exposed to shaking due to the earthquake of January 12, 2010. We can see that Leogane, located just west of the capital Port-auPrince, was struck quite severely by the earthquake. In contrast, located just north of the central plateau, 
Figure 1. Maps

(a)

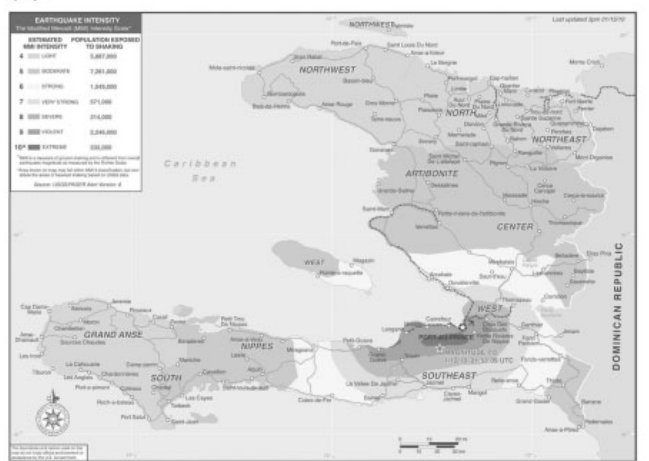

(c)

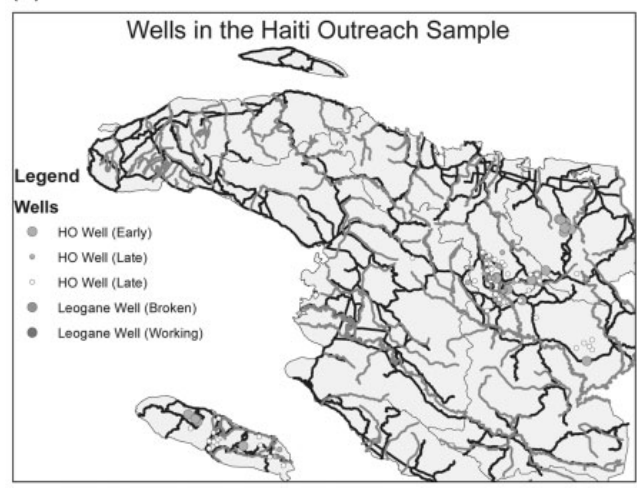

(b)

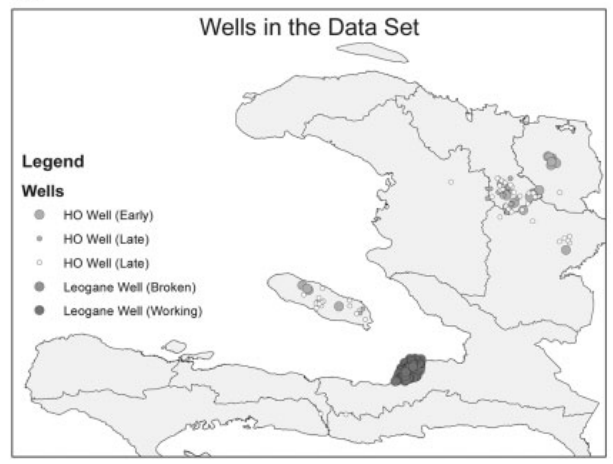

(d)

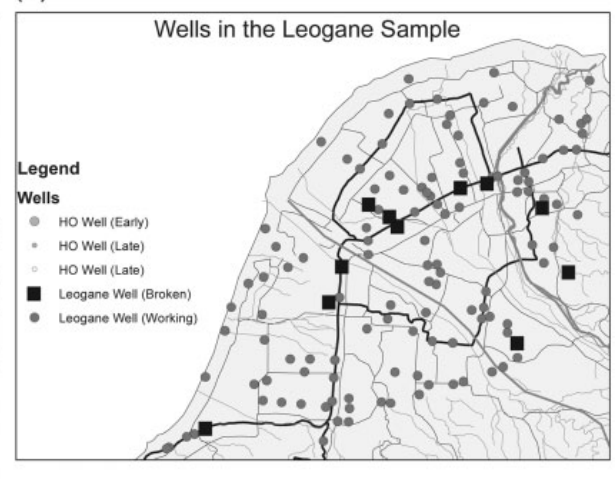

Sources: (a) USAID and (b)-(d) Haiti Outreach/MINUSTAH/author

Notes: (a) Exposure to shaking from the January 12, 2010 earthquake (b) Wells in the data set (c) Wells in the Haiti Outreach sample (d) Wells in the Leogane sample

we can see that HO's headquarters in Pignon are located near the boundary between estimates of where moderate and light shaking were felt due to the earthquake.

Figures $1 \mathrm{c}-1 \mathrm{~d}$ show the location of wells in the data set. Figure $1 \mathrm{~b}$ shows the boundaries of Haiti's 10 departments, the clustering of the Leogane wells to the west of the capital, and the clustering of HO wells near Pignon and on the island of La Gonâve. Figures 1c and 1d show the HO and Leogane samples with greater detail of the geographic data on roads and rivers used in the analysis.

Table 2 provides descriptive statistics of the functionality of wells in the two samples. In the early HO sample all 21 of the observed wells were reported as functional, with one well not observed. Of the 127 wells in the Leogane sample, 11 (8.7 percent) were broken, almost entirely due to nonfunctioning hand pumps.

Table 2. Descriptive Statistics of the Leogane and Haiti Outreach Samples

\begin{tabular}{lrcrr}
\hline Sample & $\mathbf{n}$ & Functioning (\%) & Broken (\%) & n Unobserved \\
\hline Leogane & 127 & $116(91.34)$ & $11(8.66)$ & 24 \\
Haiti Outreach & 21 & $21(100)$ & $0(0.00)$ & 1
\end{tabular}

Sources: Haiti Outreach/Author 


\section{User Fees and Access}

The HO sample provides rich data on the relationship between the percent of households ever subscribing and community characteristics. Figure 2 a shows a cumulative distribution function displaying the data on the $44 \mathrm{HO}$ wells that have information on the percent of households ever subscribing. Nearly every well has been subscribed to by over half of its community's households. The median well has been subscribed to by 64 percent of its community's households, and the 10th and 90th percentile wells had been subscribed to by, respectively, 47 and 97 percent of households in the community. Although it is difficult to gauge how these communities compare to most rural communities in Haiti, one recent survey estimated that only 27 percent of the population in an urban area had access to water from an improved source (Varma et al. 2009), and the World Bank estimates this to be true of 49 percent of the population in rural areas of the country (World Bank 2010b).

Figure 2. Subscription fees and subscription rates in the Haiti Outreach Sample

(a)

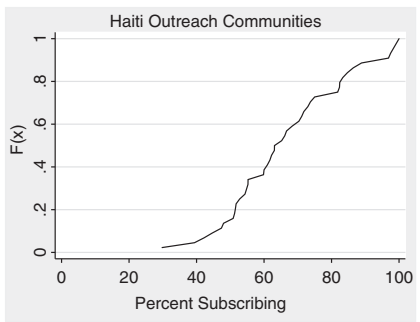

(b)

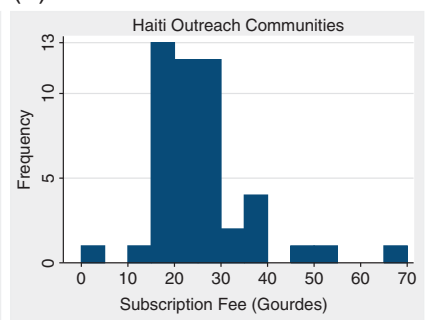

(c)

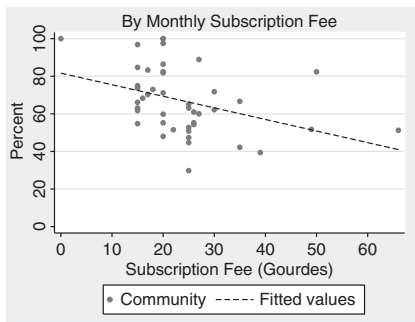

Source: Haiti Outreach

Notes: (a) CDF of percent of subscribing community members (b) Histograms of subscription fees set by communities (c) Subscription rates and subscription fees

The data on subscription fees from $48 \mathrm{HO}$ communities are presented in Figure 2b. Nearly all communities set their monthly subscription fee between 15 and 40 gourdes per month $(\approx \$ 0.40-\$ 1.00)$, with the majority of fees being between 15 and 30 gourdes and the median being 20 gourdes per month. The median HO community has 320 residents, slightly higher than the UNICEF standard of one water point per 250 people. We see the expected negative correlation between subscription fees and rates in figure $2 \mathrm{c}$, with the best linear predictor predicting that for each gourde the monthly subscription fee increases, 0.6 percent of community households will stop subscribing.

\section{Identification and the Decision Problem}

The goal of this analysis is to quantitatively characterize how money gets transformed into waterperson-years in rural Haiti. Identifying treatment effects can be less useful for this purpose than one might suppose. The approach taken here is to parameterize the preferences of the social planner while identifying the pertinent counterfactual outcomes.

In terms of the planner's problem, recall that $\omega_{i j}\left(D_{j}, X_{i j}, E_{i j}, F_{i j}, t\right)$ is an indicator for whether household $i$ with observed and unobserved characteristics $\left(X_{i j}, E_{i j}\right)$ has access to the well in community $j$ under treatment $D_{j}$ with user fee $F_{i j}$ at time $t$. Analyses of decision problems like the one stated in equation 1 typically assume either that the response function $\omega_{i j}(\cdot)$ is known, or else that the social planner decides using a subjective distribution over possible response functions (Manski 2011). This analysis aims to use empirical evidence on $\omega_{i j}(\cdot)$ in order to inform the decision problem in equation 1 , assuming that the 
difference in functionality between the Leogane and HO samples is invariant when applied to future community-based and aid communities (See Chamberlain [2000] or Bhattacharya and Dupas [2012] for related discussions.).

There are several threats to such invariance. First, note that part of the HO treatment is selecting "complier" communities. For future community-based interventions to maintain the level of efficacy documented in this analysis, this selection pattern would need to remain invariant. If HO's success is simply due to a process that selects more politically organized communities, we could add political-organization as an argument in the $\omega$ function in equation 1 and attach weights to the provision of water-person-years to households in complier communities. While preferences for poorer households might be common, it is difficult to say a priori what preferences a social planner might have over households in HO "complier" and "never-taker" communities. Thus, I assume that the social planner does not have preferences over complier status and leave the selection of complier communities as an implicit part of the HO treatment.

Second, the response function to future aid interventions might be different than those experienced by Leogane, either due to the fact that Leogane is near Haiti's capital or that it was at the epicenter of January 12th's earthquake. Wells in Leogane might have received extra attention as a result of relief efforts, but at the same time wells might have depreciated faster because they were not utilized (deWilde et al. 2008) due to the provision of free water. Usage patterns might also have changed due to population displacement. Since future experience is always outside the support of the data, the temporal stability (or lack thereof) of the response function is a subject for theory (Aliprantis 2015).

Finally, I assume that the rural status of the community and the income quantile of the household are the only characteristics $X_{i j}$ that enter as arguments of the response function $\omega_{i j}(\cdot)$. Although the Leogane and HO samples are located in different parts of Haiti, they are most importantly both from rural areas. Furthermore, both samples were judged by HO's standards to be functioning by May 2010. As a result it is plausible to attribute differences in outcomes of the treatment and control samples to differences in the operations and management procedures followed after construction, as well as the complier/never-taker compositions of the two groups of wells. ${ }^{13}$ I present empirical evidence comparing the samples in terms of some of the variables one might suspect enter as arguments of the response functions. I show why it is not feasible to include these variables in the analysis, but also that this may be inconsequential for some variables.

\section{Comparing the Leogane and HO Samples}

\section{Geographic Characteristics}

With respect to geographic characteristics, table 4 provides descriptive statistics about the spatial location of wells in the samples. The wells in the two samples are distributed similarly with respect to distance to roads, but the HO sample is distributed slightly farther away from rivers (figure 3). The wells are distributed most differently in terms of distance to the nearest well in the sample. Wells in the Leogane sample are much closer to each other, with the nearest well in the sample in Leogane being on average an order of magnitude closer than the nearest well in the HO sample. This higher density of wells in the Leogane sample is not surprising given that it also has a higher population density (table 3 ). Furthermore, this difference is not as troubling as it might otherwise be because broken wells in the Leogane sample do not appear to be distributed any closer or further from other wells than functioning wells (figures $1 \mathrm{~d}$ and $4 \mathrm{c}$.).

The variation in functionality present in the Leogane sample allows for an analysis of the relationship between functionality and well location. Looking at figures $1 \mathrm{~d}$ and $4 \mathrm{a}$, broken wells appear to be distributed closer to major roads than are functioning wells. One could imagine that these distributions could

13 When predicting how a social planner's future budget will be transformed into water-person-years, these are assumed to be the sources of variation in outcomes under the alternative interventions (aside from user fees). 
Figure 3. Densities of the Samples

(a)

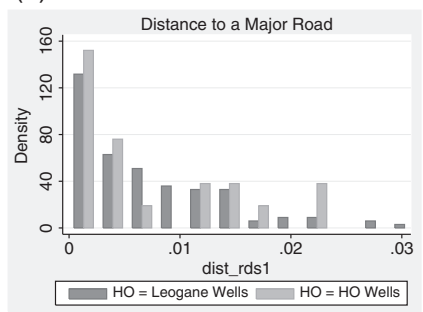

(b)

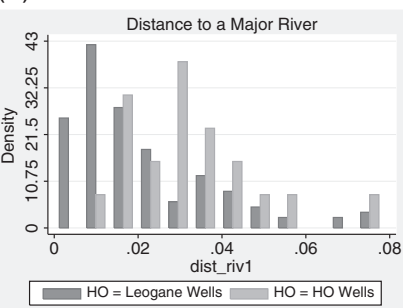

(c)

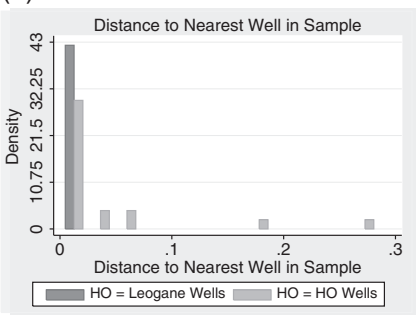

Source: Haiti Outreach/MINUSTAH

Notes: (a) Distance to nearest major road (b) Distance to nearest major river (c) Distance to nearest well

Table 3. Characteristics by Region

\begin{tabular}{|c|c|c|c|c|c|c|}
\hline \multirow[b]{2}{*}{ Arrondissement/ Commune } & \multicolumn{2}{|c|}{ Leogane Sample } & \multicolumn{4}{|c|}{ HO Sample } \\
\hline & Leogane & Port-au-Prince & St. Raphael & La Gonâve & Perches & Cap-Haïtien \\
\hline Density $\left(\mathrm{pop} / \mathrm{km}^{2}\right)$ & 456 & 3,411 & 277 & 115 & 265 & 1,321 \\
\hline Population $\geq 18(\%)$ & 59.2 & 61.8 & 53.2 & 53.3 & 54.8 & 57.9 \\
\hline Female population (\%) & 50.7 & 52.3 & 49.5 & 49.4 & 49.2 & 52.6 \\
\hline Total population $(\mathrm{n})$ & 463,140 & $2,509,939$ & 154,479 & 79,188 & 10,509 & 324,572 \\
\hline
\end{tabular}

Source: Author's calculations from the Haitian Institute of Statistics and Information (IHSI (2009)).

Table 4. Descriptive Statistics of the Leogane and Haiti Outreach Samples

\begin{tabular}{lcccccc}
\hline & \multicolumn{5}{c}{ Mean distance (std. dev.) } \\
\cline { 2 - 6 } Sample & Nearest Well & Major Road & Minor Road & Major River & Minor River \\
\hline Leogane & $0.0046^{* *}(0.0022)$ & $0.0068(0.0067)$ & $0.0021(0.0015)$ & $0.0205^{* *}(0.0170)$ & $0.0048^{*}(0.0031)$ \\
Haiti Outreach & $0.0376^{* *}(0.0687)$ & $0.0069(0.0077)$ & $0.0029(0.0031)$ & $0.0322^{* *}(0.0157)$ & $0.0081^{*}(0.0136)$ \\
\hline
\end{tabular}

Sources: Haiti Outreach/MINUSTAH/Author. ${ }^{*}$ and ${ }^{* *}$ indicate statistically different at the $5 \%$ and $1 \%$ levels.

result from different patterns in usage or different patterns in operations and maintenance due to proximity to a major road. Figures $1 \mathrm{~d}$ and $4 \mathrm{~b}$ show that broken wells also appear to be distributed closer to a major river than working wells. Broken wells do not appear to be distributed any closer or farther from other wells in the sample than functioning wells (figures $1 \mathrm{~d}$ and $4 \mathrm{c}$.). Although comparing the distributions of broken and functioning wells in the Leogane sample is a useful exercise, it must be remembered that sampling variability makes strong inferences difficult due to the small sample of broken wells.

\section{Demographic Characteristics}

Four demographic variables from IHSI (2009) represent the best source of data for comparing the Leogane and $\mathrm{HO}$ samples. The single most convincing argument for the comparability of the Leogane and $\mathrm{HO}$ samples (wrt response functions) is that both are located in rural Haiti. As shown in table 3, the population density in the Leogane area was estimated for 2009 by the IHSI to be 456 people per $\mathrm{km}^{2}$, while in the $\mathrm{HO}$ area density ranged from 115 to 277 people per $\mathrm{km}^{2}$. These densities are much lower 
Figure 4. Densities of the Samples

(a)

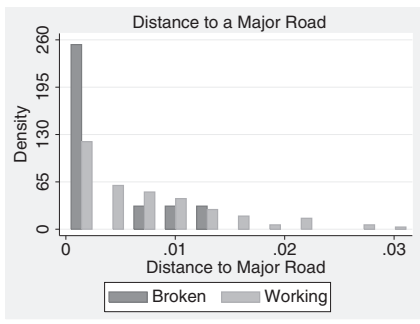

(b)

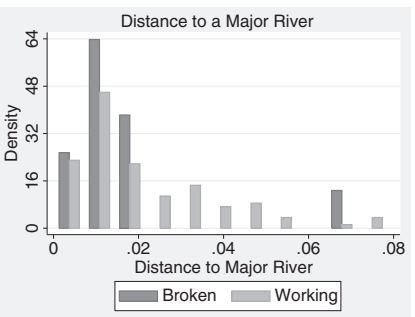

(c)

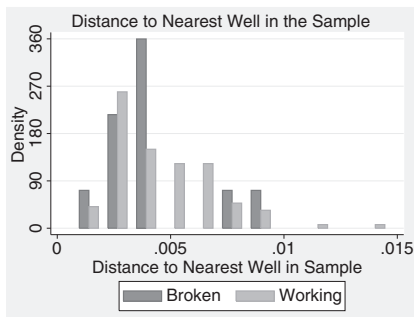

Source: Haiti Outreach/MINUSTAH/author

Notes: (a) Distance to nearest major road in the Leogane sample (b) Distance to nearest major River in the Leogane sample (c) Distance to nearest well in the Leogane sample

than those of the nearby Ouest and Nord arrondissements whose densities were, respectively, 3,411 and 1,321 inhabitants per $\mathrm{km}^{2}$ (due to the fact they include the major metropolitan areas Port-au-Prince and Cap-Haïtien, whose population densities were 15,106 and 12,235 inhabitants per $\mathrm{km}^{2}$ ).

Unfortunately, there are few additional data with which to judge the comparability of demographic characteristics in the Leogane and HO samples. The four demographic variables in IHSI (2009) are the only demographic data of which the author is aware that are available at a finer geographic level than Haiti's departments. The remainder of data in recent surveys conducted in Haiti such as IHSI/Fafo (2003), IHSI/Fafo (2005), IHSI (2005), IHSI (2009), Lunde (2009), and Lunde (2010) all pertain to coarser geographic levels such as the department or larger. ${ }^{14}$ This is problematic because Haiti's departments (analogous to states in the US) are relatively large and can be heterogeneous areas. For example, the Ouest department contains both the Leogane and Port-au-Prince arrondissements (analogous to counties in the United States), and the Nord department contains both the St. Raphael and Cap-Haitien arrondissements. Looking at the population density estimates reported in table 3, it is clear that comparing the demographic characteristics of the communities living in the areas of the Leogane and HO samples must be done at a level finer than at the department level.

\section{Quantitatively Comparing Interventions}

\section{Estimation: Preferred Assumptions and Results}

We now use the data described in section IV to empirically implement the framework described in section II, allowing us to characterize the preferences of social planners who would prefer HO's community-based intervention over the status quo, and vice-versa. Recall that throughout the ensuing analysis the treatment we are studying is not related to a well's initial construction but rather is whether the well is subsequently operated and maintained under HO's community-based approach after its construction:

$$
D_{j} \equiv \begin{cases}1 & \text { if O\&M of well j followed HO's community - based model } \\ & \text { between } t=1 \text { and } t=T ; \\ 0 & \text { if O\&M of well } j \text { followed the status quo aid model in Haiti } \\ & \text { between } t=1 \text { and } t=T .\end{cases}
$$

14 An additional variable measured at this level of aggregation does not allow for determining whether Leogane received any more or fewer refugees than did the area near Piyon (Bengtsson et al. (2010)). 
Probability of a Well Functioning: 2-Sample Binomial Distributions

Discretizing time into months over a five-year horizon (ie, $T=60$ ), we first estimate $p_{D}=\operatorname{Pr}\left[Y_{j 12}(D)=1\right]$, the probability that a well is functioning at $t=12$. Define $Z_{1}$ to be the number of successes in the $\mathrm{HO}$ sample and $Z_{0}$ to be the number of successes in the Leogane sample. We assume these random variables are drawn from separate binomial distributions, $Z_{1} \sim \operatorname{binomial}\left(n_{1}, p_{1}\right)$ and $Z_{0} \sim \operatorname{binomial}\left(n_{0}, p_{0}\right)$. Define $\Delta=p_{1}-p_{0}$ and $q_{j}=1-p_{j}$. The Wald confidence interval $(\mathrm{CI})$ for $\Delta$ is

$$
\hat{\Delta} \pm z_{\alpha / 2} \sqrt{\hat{p_{1}} \hat{q}_{1} / n_{1}+\hat{p_{0}} \hat{q_{0}} / n_{0}} \text {. }
$$

Agresti's CI is analogous to that in equation 4, but where the researcher has added one success and one failure to each sample so that $\hat{p}_{j}=\left(z_{j}+1\right) /\left(n_{j}+2\right) .{ }^{15}$

Table 5 shows Wald and Agresti estimates for our samples. The table shows there is a difference in the binomial proportion parameters of the samples between 8 and 9 percent. These differences are statistically significant at the 5 percent level under both the Wald and Agresti assumptions. ${ }^{16}$

Table 5. $\hat{\Delta}=\hat{p_{1}}-\hat{p_{0}}$ and Confidence Intervals

\begin{tabular}{lcc}
\hline Assumptions & $\hat{\Delta}$ & $\hat{\Delta} \pm 1.96 \sqrt{p_{1} \hat{q_{1}} / n_{1}+\hat{p_{0}} \hat{q}_{0} / n_{0}}$ \\
\hline Wald & 0.087 & {$[0.022,0.151]$} \\
Agresti & 0.079 & {$[-0.018,0.175]$} \\
\hline
\end{tabular}

Sources: Haiti Outreach/author

Given our estimate of $p_{D}$ from table 5, we proceed by assuming that in each period functioning wells break down with some probability $\pi_{B}(D)$. A broken well is broken for at least one month but is repaired with probability $\pi_{R}(D)$ during each of the subsequent months that it remains broken. Assuming that the functionality and repair of wells are negative binomial processes, $\hat{\pi}_{B}(D=0)=1 / 25$ is a conservative estimate, and the implied repair rate is $\hat{\pi}_{R}(D=0)=5 / 6$. We also assume $\hat{\pi}_{B}(D=1)=1 / 100$ and $\hat{\pi}_{R}(D=1)=1 .^{17}$

\section{The Effect of User Fees on Access}

It is difficult to assess how much user fees restrict access in HO's community-based interventions. Ahuja et al. (2010) provide related evidence suggesting that in this context stated and revealed preferences could be quite divergent. In terms of revealed preferences, while the literature has documented a high price elasticity of demand, the evidence from free interventions suggests that this elasticity is likely to be driven by factors other than a household's relative income. For example, the evidence suggests that 60 or 70 percent might be the least upper bound on take-up of water interventions in rural areas even when provision is free and convenient. Household water treatment at the point of use tends to achieve take-up rates on the order of 70 percent with frequent visits and reminders to subjects (Ahuja et al. 2010).

15 Brown et al. (2001) show that estimates of the analogous Wald CI for a binomial proportion do not have desirable coverage properties, especially when $n p$ is very low as it is in our case. Brown and Li (2005) evaluate the performance of several alternative CIs for the difference of two binomial proportions, and they find that Agresti's CI (Agresti and Caffo (2000)) performs conservatively when $\min \left(n_{0}, n_{1}\right)$ is low.

16 Since we do not observe any broken wells in the HO sample, in the Wald estimates we compute standard errors under the assumption $\hat{p_{1}}=0.99$.

17 The appendix A2 presents derivations of these probabilities. These numbers are conservative because HO staff estimate that 50 percent of aid wells tend to be broken down by the end of a given year, and also because staff members of JEN provided the author with information that they had rehabilitated 97 handpumps in Leogane in the time period under investigation (Papadimitriou (2011)). 
The evidence from rural Kenya reported in Kremer et al. (2009) is that only 60 percent of people used chlorine when a field worker delivered it to their houses for free.

The size of the HO user fee also suggests that income is unlikely to be the key driver of the price elasticity of demand. At 20 gourdes per month, the median $\mathrm{HO}$ user fee is 0.5 percent of the average monthly income of rural families in Haiti (Lunde 2010, 50) and 1.2, 0.6, and 0.3 percent of monthly income for, respectively, the 25th, 50th, and 75th percentiles of rural households in Haiti (Lunde 2009). ${ }^{18}$ Such costs would qualify as "affordable" or nearly so under the most common definitions used in the United States: The US Environmental Protection Agency has defined affordable expenditures on water and wastewater as those under 2.0 (1993) and 2.5 (1998) percent of median household income, with a burden of 2.0 percent of income being the generally accepted threshold of determining affordability for low-income households (Fisher et al. 2005). ${ }^{19}$

The relative size of the HO user fee compares favorably to the fees many low-income households in the United States pay for their water. WIN (2000) estimated that 18 percent of US households, many of them poor, paid more than 4 percent of their income on their water and sewer bill in 1997, with projections that this would increase to 22 percent of US households by 2009. The hypothetical average water bill from the analysis in Stratus Consulting (2013) would represent 2.0 percent of household income for a family of four at the federal poverty threshold. ${ }^{20}$ These costs are also well below the typical monthly cost of cell phone service, which is estimated by HO staff to be around 50 gourdes per month and to have near universal take-up (van Dine 2014).

With these considerations in mind, we nevertheless assume that the only observed factor contributing to household i's choice to register for their community $j$ 's well is its relative income (ie, $X_{i} \equiv$ income quantile $q_{i}$ ), with access restricted for those below some income threshold $q^{*}$ when any fee is charged. This yields water-person-years provided as follows:

$$
\omega_{i j}\left(D_{j}, q_{i}, E_{i}, F_{j t}, t\right)=\left\{\begin{array}{lll}
1\left\{q_{i} \geq q^{*}\right\} 1\left\{E_{i} \geq 0\right\} & \text { if } & Y_{j t}=1 \text { and } F_{i j}>0 \\
1\left\{E_{i} \geq 0\right\} & \text { if } \quad Y_{i t}=1 \text { and } F_{i j}=0 \\
0 & \text { if } \quad Y_{i t}=0 .
\end{array}\right.
$$

What is the appropriate $q^{*}$ given the empirical evidence just discussed? One could argue that $q^{*}$ is 0 , since committees are able to price discriminate and charge poor families less for access to wells. Since the median percentage of households never registering with their community's well is 36 percent in the HO sample, in the preferred assumptions user fees restrict access under HO's model to the bottom quintile of households, with the remaining 16 percent of households not registering due to preferences for other water sources. That is, we assume $q^{*}=0.20$ in equation 5 , with unobserved factors $E_{i}$ accounting for the remaining 16 percent of households without access (i.e., for which $\omega_{i j}=0$ ).

\section{Total Costs of Interventions to the Social Planner}

The ratio $J_{0} / J_{1}$ is all that is missing to be able to simulate equation 3. Denote the price of fixing broken wells as $C($ repair, $D)$ and the price of constructing a well as $C($ construct, $D)$. The total cost of well $j$ over the

18 Assuming the median rural household has 5 members (Lunde (2009), table 1.11), then the 25th, 50th, and 75th percentiles of monthly household income are, respectively, 1,665, 3,335, and 6,250 gourdes (Lunde (2009), table 7.11). These costs are also comparable to estimates of the costs for providing chlorine (Lantagne et al. (2007)), and are below those elicited in a contingent valuation study previously conducted in Haiti (Whittington et al. (1990), Diamond and Hausman (1994)).

19 Comparisons would most appropriately be to water expenses alone, excluding those from wastewater. Stratus Consulting (2013) assume that water makes up 40 percent of water/wastewater expenses, which would yield a definition of "affordable" water costs for low-income households of under 0.8 percent of income.

20 Author's calculation made to exclude wastewater bill. 
$T$ periods is $T C\left(D_{j}\right)=C_{j}\left(\right.$ construct,$\left.D_{j}\right)+\sum_{t=1}^{T} C_{j}\left(\right.$ repair $\left._{t}, D_{j}\right)$. HO estimates that drilling or rehabilitating a well typically costs between $\$ 4$ and $\$ 9,000$, with a mean value of about $\$ 5,000$. Since HO's management training costs $\$ 2,000$, and the well shelter an additional $\$ 2,000$, we assume $C($ construct, $D=1)=\$ 9,000$, $C($ construct,$D=0)=\$ 5,000, C($ repair,$D=1)=0$ and $C($ repair,$D=0)=\$ 5,000 .^{21}$

Given these estimates of $\hat{C}($ repair, $D)$ and $\hat{C}($ construct, $D)$, together with the estimates $\hat{\pi}_{B}(D)$ and $\hat{\pi}_{R}(D)$ obtained above, the ratio of wells that can be financed with a fixed sum of money under the different management styles, $J_{0} / J_{1}$, is estimated using the average ratio of total costs over $T=60$ months in Monte Carlo simulations of 10,000 wells, $\frac{E[T C(1)]}{E[T C(0)]}$.

\section{The Equity Efficiency Tradeoff between Interventions}

Given the estimates just detailed, we use $N$ Monte Carlo simulations to estimate the ratio of expected utilities from equation 3 for any planner's preferences parameterized by $\theta$ :

$$
\mathbb{E}\left[\frac{U(1)}{U(0)} \mid \theta\right]=\frac{\mathbb{E}[W(1) \mid \theta]}{\mathbb{E}[W(0) \mid \theta]} \frac{J_{1}}{J_{0}}=\frac{\mathbb{E}[W(1) \mid \theta]}{\mathbb{E}[W(0) \mid \theta]} \frac{\mathbb{E}[T C(0)]}{\mathbb{E}[T C(1)]},
$$

where

$$
\mathbb{E}[W(D) \mid \theta]=\sum_{j=1}^{N} \frac{1}{N} \sum_{t=1}^{T} \sum_{q=0}^{100} \sum_{i=1}^{I_{j}} \frac{1}{I_{j}} \delta\left(\theta, q_{i}\right) \omega_{i j}\left(D_{j}, q_{i}, E_{i}, F_{j}, t\right)
$$

and

$$
\mathbb{E}[T C(D)]=\sum_{j=1}^{N} \frac{1}{N}\left[C_{j}\left(\text { construct }, D_{j}\right)+\sum_{t=1}^{T} C_{j}\left(\text { repair }_{t}, D_{j}\right)\right] .
$$

Simulations are run in terms of the expected water provided to a given quantile,

$$
\mathbb{E}[W(D) \mid \theta]=\sum_{t=1}^{T} \sum_{q=0}^{100} \delta(\theta, q) \bar{\omega}(D, q, t)
$$

where

$$
\bar{\omega}(D, q, t)=\sum_{j=1}^{N} \frac{1}{N} \sum_{i=1}^{I_{j}} \frac{1}{\sum_{i=1}^{I_{j}} \mathbf{1}\left\{q_{i}=q\right\}} \mathbf{1}\left\{q_{i}=q\right\} \omega_{i j}\left(D_{j}, q_{i}, E_{i}, F_{j}, t\right)
$$

and it is assumed that $I_{j}=I$ for all communities and that all communities have the same joint distribution of $\left(X_{i}, E_{i}\right) \equiv\left(q_{i}, E_{i}\right)$. Recalling that since $\mathbb{E}\left[\frac{U(1)}{U(0)} \mid \theta\right]$ will be monotonic in $\theta$ under our assumptions, we can find the unique $\theta^{*}$ characterizing social planners indifferent between interventions (i.e., such that $\left.\mathbb{E}\left[\frac{U(1)}{U(0)} \mid \theta^{*}\right]=1\right)$.

In order to interpret the preference parameter $\theta$, I report the implied preference relation in terms of the number of households provided with a water-person-year at a given income level and one household at the lowest income level. Given $\theta$, a social planner indifferent between providing water-person-years to $\bar{\omega}^{*}\left(\cdot, q_{0}, t\right)$ households at income quantile $q_{0}$ and $\bar{\omega}^{*}\left(\cdot, q_{1}, t\right)$ households at income quantile $q_{1}$ requires:

21 I do not explicitly account for the costs of ongoing staff necessary under community-based and aid interventions because these costs are difficult to measure. I consider the estimation results under the assumption that $C($ repair, $D=0)$ $=\$ 4,000$ to serve as a robustness check in the case that there were significant differences in these costs favoring the aid approach, although it is plausible that long-term costs would favor the community-based model due to its use of Haitian staff. 


$$
\delta\left(\theta, q_{0}\right) \bar{\omega}^{*}\left(\cdot, q_{0}, t\right)=\delta\left(\theta, q_{1}\right) \bar{\omega}^{*}\left(\cdot, q_{1}, t\right) .
$$

Letting $q_{0}=0$ and normalizing $\bar{\omega}^{*}\left(\cdot, q_{0}, t\right)$ to 1 , we can see that given $\theta$, a social planner would be indifferent between providing a water-person-year to one household at the poorest income level and water-person-years to

$$
\bar{\omega}^{*}\left(\cdot, q_{1}, t\right)=\frac{\delta\left(\theta, q_{0}\right)}{\delta\left(\theta, q_{1}\right)} \bar{\omega}^{*}\left(\cdot, q_{0}, t\right)=\frac{1}{\delta\left(\theta, q_{1}\right)}
$$

households at the $q_{1}$ income quantile.

It is useful to know some characteristics of the income distribution in rural Haiti before examining figure 5, which shows preferences over providing water to households at various percentiles of the income distribution. According to the Haiti Youth Survey conducted in 2009, the 25th, 50th, and 75th percentiles of monthly per-capita income in rural Haiti are, respectively, 333, 667, and 1,250 Haitian gourdes (HTG; Lunde 2009, table 7.11). Using the April 1, 2009, exchange rate as in Lunde (2010) (1 USD $=39 \mathrm{HTG})$, the $25 \mathrm{th}$, 50th, and 75th percentiles of daily per-capita income are then $0.28,0.57$, and 1.07 US dollars. Adjusting for Purchasing Power Parity (PPP) in rural Haiti as in Lunde (2010) (USD $0.8=$ PPP USD 1.3), these percentiles are, respectively, 0.46, 0.93, and 1.74 PPP US dollars. ${ }^{22}$

Figure 5. Estimated Preferences of an Indifferent Social Planner

(a)

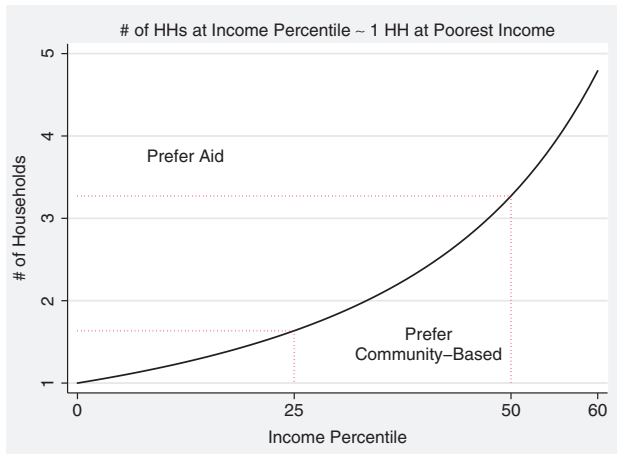

(b)

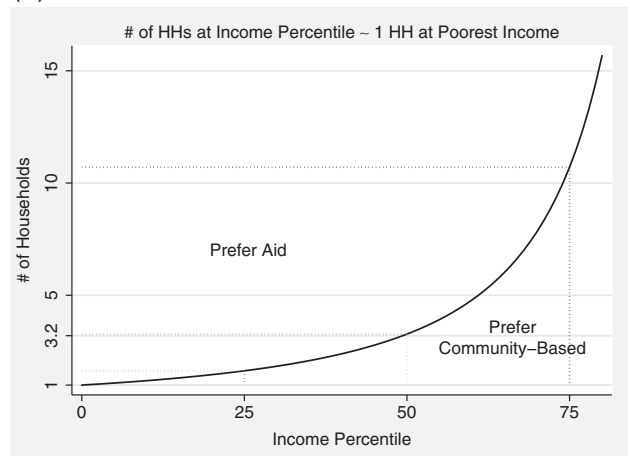

Source: Author's analysis based on data described in the text

Now that we are equipped with information about the income distribution in rural Haiti, we are capable of interpreting figure 5 . The solid line represents the preferences of a social planner indifferent between community-based and aid interventions under our preferred assumptions $\left(\hat{\theta}^{*}=1.7\right)$. Such a social planner places very little relative weight on much of the income distribution. In exchange for providing water to one household at the poorest income level, such a planner would be willing to forego providing water to $1.6,3.2$, or 10.7 households with daily per-capita incomes of $0.46,0.93$, and 1.74 PPP US dollars, respectively. In other words, a preference for aid interventions indicates that one is willing to sacrifice providing water-person-years to many households with incomes under the poverty line (Ravallion et al. 2009) in order to provide water-person-years to the very poorest households.

Table 6 presents estimates of $\theta^{*}$ under alternative assumptions that, relative to the preferred assumptions, are either more favorable to the community-based or aid interventions. If only the 10 poorest percentiles of income are excluded due to user fees, $\hat{\theta}^{*}=5.1$ and the indifferent social planner all but entirely discounts providing water to above median households. Recalling the discussion in section VI, a

22 See Lunde (2010) for a discussion of the PPP calculation for Haiti. 
Table 6. Parameter Assumptions and $\hat{\theta}^{*}$

\begin{tabular}{|c|c|c|c|}
\hline & \multicolumn{3}{|c|}{ Maintained assumptions } \\
\hline & Preferred & Alternative favoring community-based & Alternative favoring aid \\
\hline \multicolumn{4}{|l|}{ Subscription } \\
\hline$q^{*}$ & 0.20 & 0.10 & 0.27 \\
\hline \multicolumn{4}{|l|}{ Breakdown/repair } \\
\hline$\pi_{B}(H O=0)$ & $1 / 25$ & $1 / 25$ & $1 / 25$ \\
\hline$\pi_{B}(H O=1)$ & $1 / 100$ & $1 / 100$ & $1 / 100$ \\
\hline$\pi_{R}(H O=0)$ & $5 / 6$ & $5 / 6$ & $5 / 6$ \\
\hline$\pi_{R}(H O=1)$ & 1 & 1 & 1 \\
\hline \multicolumn{4}{|l|}{ Costs } \\
\hline$C($ construct,$H O=0)$ & 5,000 & 5,000 & 5,000 \\
\hline$C($ construct,$H O=1)$ & 9,000 & 9,000 & 9,000 \\
\hline$C($ repair,$H O=0)$ & 5,000 & 5,000 & 4,000 \\
\hline$C($ repair,$H O=1)$ & 0 & 0 & 0 \\
\hline \multicolumn{4}{|l|}{ Time horizon } \\
\hline$T$ & 60 & 60 & 60 \\
\hline \multicolumn{4}{|l|}{ Parameter estimate } \\
\hline$\hat{\theta}^{*}$ & 1.71 & 5.05 & 0.42 \\
\hline \multicolumn{4}{|c|}{ Providing water to $1 \mathrm{HH}$ at $q=0$} \\
\hline$\sim \#$ HHs at $q=0.25$ & 1.6 & 4.3 & 1.1 \\
\hline$\sim \#$ HHs at $q=0.50$ & 3.3 & 33.1 & 1.3 \\
\hline$\sim \#$ HHs at $q=0.75$ & 10.7 & $1,097.5$ & 1.8 \\
\hline
\end{tabular}

Sources: 10,000 simulations based on data from Haiti Outreach/JEN/author.

$q^{*}$ of even 0.10 may be high. In the case that HO's subscription fees are indeed responsible for screening even more households (i.e., $q^{*}=0.28$ ), and repair/staffing costs are lower for aid interventions, $\hat{\theta}^{*}=0.4$. Even making such assumptions without empirical justification in order to favor the aid intervention, a social planner would still need to highly discount the outcomes of poor households.

\section{Discussion}

An important implication of these results for the literature is that community-based property rights arrangements allow for a third way between open access and privatization. The property rights arrangement in the $\mathrm{HO}$ model fall somewhere between the communal and private property rights definitions in Kremer et al. (2011), in that the property rights regime in the HO model is not one of open access, nor of profit-maximizing well owners. Well owners are communities that, while able to restrict access, are more accurately described as water-person-years-maximizing.

This distinction matters because, at least in the context of water infrastructure in rural Haiti, user fees as implemented in the community-based approach do not appear to have detrimental effects on equity. First, as discussed in section VI, it appears unlikely that the price elasticity of demand is driven by income in the context studied in this analysis. In addition to low fees relative to income, another reason is that committees are not profit-maximizing, so they actually price discriminate and charge lower fees for poor households. Furthermore, the analysis shows that even making conservative assumptions about the equity implications of user fees, the community-based efficiency gains due to more consistent service (Baisa et al. 2010) are so great that they would outweigh equity concerns even for social planners with a strong preference for the poor.

A related point about causality is made in Mansuri and Rao (2004) and Mansuri and Rao (2007), who note that we might be most interested in thinking about how the community-based approach would 
compare to a top-down, government-led intervention, rather than an aid intervention. At this point in time, however, the weakness of the government in Haiti renders such a discussion theoretical (Collier 2010).

\section{Conclusion}

This paper evaluated the community-based model developed by Haiti Outreach (HO), which is focused on training communities to operate and maintain wells in rural Haiti. I found that HO's communitybased model has large efficiency gains relative to the status quo aid model in rural Haiti. Wells whose construction, operations, and maintenance were all overseen by $\mathrm{HO}$ were 8.7 percentage points more likely to be functioning after one year than wells whose construction alone was overseen by HO.

Because user fees are typically a part of HO's model, which raise concerns about equity, I quantified the equity-efficiency tradeoff between community-based and aid interventions by determining the preferences of a social planner indifferent between these types of water infrastructure interventions. Since HO's user fees are only 0.6 percent of median income in rural Haiti, under most specifications the efficiency gains of the community-based model outweigh the equity concerns addressed by the aid model.

In Haiti, the choice between long-term development and short-term relief is often seen as mutually exclusive. Haiti Outreach has developed a community-based approach that can serve as a model for how the many NGOs providing vital, urgent services in Haiti can do so while building, rather than undermining, the capacity of local communities to make and enact collective decisions. More generally, there are likely to be other contexts without the presence of a strong public sector in which community-based property rights arrangements offer an attractive alternative between open access and privatization.

\section{References}

Agresti, A., and B. Caffo. 2000. "Simple and Effective Confidence Intervals for Proportions and Difference of Proportions Result from Adding Two Successes and Two Failures.” American Statistician 54 (4): 280-88.

Ahuja, A., M. Kremer, and A. P. Zwane. 2010. "Providing Safe Water: Evidence from Randomized Evaluations." Annual Review of Resource Economics 2 (1): 237-56.

Aliprantis, D. 2013, February 1. "Building Infrastructure, Physical and Otherwise, in Rural Haiti.” Timmy Global Health Blog Post.

- 2015. "Covariates and Causal Effects: The Problem of Context." Federal Reserve Bank of Cleveland Working Paper 13-10R.

Baisa, B., L. W. Davis, S. W. Salant, and W. Wilcox. 2010. “The Welfare Costs of Unreliable Water Service.” Journal of Development Economics 92 (1): 1-12.

Bengtsson, L., X. Lu, R. Garfield, A. Thorson, and J. Von Schreeb. 2010. "Internal Population Displacement in Haiti: Preliminary Analyses of Movement Patterns of Digicel Mobile Phones: 1 January to 11 March 2010." Sweden: Karolinska Institute, Center for Disaster Medicine.

Bennett, D. 2012. "Does Clean Water Make You Dirty? Water Supply and Sanitation in the Philippines." Journal of Human Resources 47 (1): 146-73.

Bhattacharya, D. and P. Dupas. 2012. "Inferring Welfare Maximizing Treatment Assignment under Budget Constraints." Journal of Econometrics 167 (1): 168-96.

Brick, T., B. Primrose, R. Chandrasekhar, S. Roy, J. Muliyil, and G. Kang. 2004. "Water Contamination in Urban South India: Household Storage Practices and Their Implications for Water Safety and Enteric Infections." International Journal of Hygiene and Environmental Health 207: 473-80.

Briscoe, J., and D. de Ferranti. 1988. Water for Rural Communities: Helping People Help Themselves. Washington, DC: The World Bank.

Brown, L., T. T. Cai, and A. DasGupta. 2001. “Interval Estimation for a Binomial Proportion.” Statistical Science 16 (2): 101-33. 
Brown, L., and X. Li (2005). Confidence intervals for two sample binomial distribution. Journal of Statistical Planning and Inference 130 (1-2), 359-375.

CEPR. 2011, April 19. "Haitian Companies Still Sidelined from Reconstruction Contracts." Washington, DC: Center for Economic and Policy Research.

Chamberlain, G. 2000. "Econometrics and Decision Theory." Journal of Econometrics 95 (2): 255-83.

Clinton, B. 2010, March 25. "Consultation with the Global NGO Community on Building Back Better in Haiti." UN Office of the Special Envoy for Haiti. Speech at New York University.

Cohen, J., and P. Dupas 2010. "Free Distribution or Cost-Sharing? Evidence from a Randomized Malaria Prevention Experiment." Quarterly Journal of Economics 125 (1): 1-45.

Collier, P. 2010, March 8. "The Crisis in Haiti Shows We Need a New Approach to NGOs." The Independent.

De Wilde, C. K., A. Milman, Y. Flores, J. Salmerón, and I. Ray. 2008. "An Integrated Method for Evaluating Community-based Safe Water Programmes and an Application in Rural Mexico." Health Policy and Planning 23: 452-64.

Diamond, P. A., and J. A. Hausman. 1994. "Contingent Valuation: Is Some Number Better than No Number?” Journal of Economic Perspectives 8 (4): 45-64.

Dupuy, A. 2010. "Disaster Capitalism to the Rescue: The International Community and Haiti after the Earthquake." NACLA Report on the Americas 43 (4): 14-19.

Esrey, S. A. 1996. "Waste, Water, and Well-Being: A Multicountry Study." American Journal of Epidemiology 143 (6): 608-22.

Esrey, S. A., J. B. Potash, L. Roberts, and C. Shiff. 1991. "Effects of Improved Water Supply and Sanitation on Ascariasis, Diarrhea, Dracunculiasis, Hookworm Infection, Schistosomiasis, and Trachoma." Bulletin of the World Health Organization 69 (5): 609-21.

Fisher, P., M. Sheehan, and R. Colton. 2005, March/April. "Defining 'Affordable' Water Rates for Low-Income Affordability Programs.” FSC's Law \& Economics Insights 05 (2): 1-5.

Galiani, S., P. Gertler, and E. Schargrodsky. 2005. "Water for Life: The Impact of the Privatization of Water Services on Child Mortality.” Journal of Political Economy 113 (1): 83-120.

Glum, J. 2014, August 8. "Relief Organizations Need to Think Long-Term, UF Research Shows." University of Florida Emerging Pathogens Institute: Haiti Research Lab.

HRF. 2010, June 2. "Pledges up to 11 Billion Dollars Confirmed during the World Summit for the Future of Haiti." Haiti Reconstruction Fund, Santo Domingo. Retrieved at: http://www.haitireconstructionfund.org/hrf/news0602.

IHSI. 2005. Inventaire des Ressources et Potentialités d'Haiti. Retrieved at http://www.ihsi.ht/publication_cd_inven taire.htm: l'Institut Haitien de Statistique et d'Informatique (IHSI).

IHSI. 2009, March. Population Totale, Population de 18 Ans et Plus Menages et Densites Estimes en 2009. Retrieved at http://www.ihsi.ht/pdf/projection/POPTOTAL\&MENAGDENS_ESTIM2009.pdf: l'Institut Haïtien de Statistique et d'Informatique (IHSI).

IHSI/Fafo. 2003. Enquête sur les Conditions de Vie en Haïti, Volume I. Retrieved at http://www.ihsi.ht/produit_enq_ nat_ecvh.html: l'Institut Haïtien de Statistique et d'Informatique (IHSI), Ministere de l'Economie et des Finances de l'Republique d'Haïti, Fafo Institute for Applied International Studies, United Nations Development Program.

IHSI/Fafo. 2005. Enquête sur les Conditions de Vie en Haïti, Volume II. Retrieved at http://www.ihsi.ht/produit_enq_ nat_ecvh.html: l'Institut Haïtien de Statistique et d'Informatique (IHSI), Ministere de l'Economie et des Finances de l'Republique d'Haïti, Fafo Institute for Applied International Studies, United Nations Development Program.

Isham, J., and S. Kähkönen. 2002. "Institutional Determinants of the Impact of Community-based Water Services: Evidence from Sri Lanka and India." Economic Development and Cultural Change 50 (3): 667-91.

Iyer, P., J. Davis, and E. Yavuz. 2006. "Rural Water Supply, Sanitation, and Hygiene: A Review of 25 years of World Bank Lending (1978-2003)." Water Supply \& Sanitation Working Notes (10).

Jalan, J., and M. Ravallion. 2003. "Does Piped Water Reduce Diarrhea for Children in Rural India?” Journal of Econometrics 112 (1): 153-73.

Jessoe, K. 2013. "Improved Source, Improved Quality? Demand for Drinking Water Quality in Rural India.” Journal of Environmental Economics and Management 66 (3): 460-75.

Katz, J. M. 2013. The Big Truck That Went By: How the World Came to Save Haiti and Left Behind a Disaster. Basingstroke: Palgrave Macmillan.

—. 2014, March 12. "Haiti's Shadow Sanitation System." The New Yorker. 
Khwaja, A. I. 2009. "Can Good Projects Succeed in Bad Communities?” Journal of Public Economics 93 (7-8): 899-916.

Koestler, A. G., M. A. Koestler, and L. Koestler. 2009. "Coverage as a Misleading Development Goal: The Concept of Water-Person-Years." In Water, Sanitation and Hygiene: Sustainable Development and Multisectoral Approaches, Addis Ababa. 34th Water, Engineering and Development Centre (WEDC) International Conference.

Kremer, M., J. Leino, E. Miguel, and A. P. Zwane. 2011. "Spring Cleaning: Rural Water Impacts, Valuation, and Institutions.” Quarterly Journal of Economics 126 (1): 145-205.

Kremer, M., and E. Miguel. 2007. "The Illusion of Sustainability." Quarterly Journal of Economics 122 (3): 1007-65.

Kremer, M., E. Miguel, S. Mullainathan, C. Null, and A. Zwane. 2009. "Making Water Safe: Price, Persuasion, Peers, Promoters, or Product Design?" Mimeo., Harvard.

Lantagne, D. S., R. Quick, and E. D. Mintz. 2007. "Household Water Treatment and Safe Storage Options in Developing Countries: A Review of Current Implementation Practices.” In M. Parker, A. Williams, and C. Youngblood, eds., Water Stories: Expanding Opportunities in Small Scale Water and Sanitation Projects. Washington, DC: Woodrow Wilson International Center.

Lawrence, P., J. Meigh, and C. Sullivan. 2002. “The Water Poverty Index: An International Comparison.” Keele Economics Research Papers 2002/19.

Lunde, H. 2009. "Haiti Youth Survey: Volume I Tabulation Report.” Retrieved at http://www.fafo.no/pub/rapp/ 20143/20143.pdf: Fafo.

—. 2010. "Haiti Youth Survey: Volume II Analytical Report.” Retrieved at http://www.fafo.no/pub/rapp/20188/ 20188.pdf: Fafo.

Manski, C. F. 2011. "Choosing Treatment Policies under Ambiguity." Annual Review of Economics 3: 25-49.

Mansuri, G., and V. Rao. 2004. "Community-based and -driven Development: A Critical Overview." The World Bank Research Observer 19 (1): 1-39.

- 2007. "Update Note on Community-based and-driven Development." Mimeo., The World Bank.

McKenzie, D., and I. Ray. 2004. "Household Water Delivery Options in Urban and Rural India." Stanford Center for International Development Working Paper No. 224.

Miguel, E., and M. K. Gugerty. 2005. "Ethnic Divisions, Social Sanctions, and Public Goods in Kenya." Journal of Public Economics 89 (11-12): 2325-68.

Narayan, D. 1993. Participatory Evaluation: Tools for Managing Change in Water and Sanitation. Washington, DC: The World Bank.

Ocwieja, S., H. Bigelow, R. Michel, and K. N. Van Dine. 2011. "Community Management and Revenue Transformation Model Working in Rural Haiti.” Pignon, Haiti: Haiti Outreach. Prepared for the 35th Water, Engineering and Development Centre (WEDC) International Conference.

Ostrom, E. 2014. “Do Institutions for Collective Action Evolve?” Journal of Bioeconomics 16 (1): 3-30.

Ostrom, E., and R. Gardner. 1993. "Coping with Asymmetries in the Commons: Self-governing Irrigation Systems Can Work." Journal of Economic Perspectives 7 (4): 93-112.

Palmer, N., D. H. Mueller, L. Gilson, A. Mills, and A. Haines. 2004. "Health Financing to Promote Access in Low Income Settings: How Much Do We know? Lancet 364: 1365-70.

Papadimitriou, D. 2011, April 29. Personal communication: Email. Japanese Emergency NGO (JEN).

Parker, R., and T. Skytta. 2000. "Rural Water Projects: Lessons from OED Evaluations." World Bank Operations Evaluation Department Working Paper Series No. 3.

Peterson, B. 2008. "Roads to Development: A Geospatial Study of the Political Economy of Road Building in Haiti." Mimeo., Stanford University.

Ramachandran, V., and J. Walz. 2012. "Haiti: Where Has All the Money Gone?” Center for Global Development Policy Paper 004.

Ravallion, M., S. Chen, and P. Sangraula. 2009. "Dollar a Day Revisited.” World Bank Economic Review 23 (2): $163-84$.

Schuller, M. 2007. "Invasion or Infusion? Understanding the Role of NGOs in Contemporary Haiti." Journal of Haitian Studies 13 (2): 96-119.

- 2012. Killing With Kindness: Haiti, International Aid, and NGOs. New Brunswick, NJ: Rutgers University Press. 
Schwartz, T. T. 2010a, January 19-26. “Is This Anarchy?” Now Toronto 29 (21).

-2010b, March 10. Part I: How to Save the NGO Sector from Itself. Open Salon.

-2010c, March 10. Part II: Save NGO Sector from Itself (and Haiti from the NGOs). Open Salon.

Stratus Consulting. 2013. Affordability Assessment Tool for Federal Water Mandates. Boulder, CO: United States Conference of Mayors, The American Water Works Association, and The Water Environment Federation.

Trouillot, M.-R. 1990. Haiti, State against Nation: The Origins and Legacy of Duvalierism. Monthly Review Press.

UNDP-World Bank. 1999. Water for India's Poor: Who Pays the Price for Broken Promises? New Delhi: UNDP-

World Bank Water and Sanitation Program-South Asia.

USIP. 2010. "Haiti: A Republic of NGOs?" United States Institute of Peace: Peace Brief, Volume 23, Washington.

van Dine, N. 2014, April 14. Personal Communication: Email. Pignon, Haiti: Haiti Outreach.

Varma, M. K., M. L. Satterthwaite, A. M. Klasing, T. Shoranick, J. Jean, D. Barry, M. C. S. Fawzi, J. McKeever, and E. Lyon. 2009. "Wòch nan soley: The Denial of the Right to Water in Haiti." Health and Human Rights in Practice $10(2): 67-89$.

Waddington, H., and B. Snilstveit. 2009. "Effectiveness and Sustainability of Water, Sanitation, and Hygiene Interventions in Combating Diarrhoea. Journal of Development Effectiveness 1 (3): 295-335.

Whittington, D., J. Briscoe, X. Mu, and W. Baron. 1990. "Estimating the Willingness to Pay for Water Services in

Developing Countries: A Case Study of the Use of Contingent Valuation Surveys in Southern Haiti." Economic Development and Cultural Change 38 (2): 293-311.

WHO. 2008. "Progress on Drinking Water and Sanitation: Special Focus on Sanitation." World Health Organization, Geneva and United Nations Children's Fund, New York.

WIN. 2000. Clean and Safe Water for the 21st Century. Englewood, CO: Water Infrastructure Network.

World Bank. 1988. Road Deterioration in Developing Countries: Causes and Remedies. Washington, DC: The World Bank.

World Bank. 1996. The World Bank Participation Sourcebook. Washington, DC: The World Bank.

World Bank. 2006, October 20. "Interim Poverty Reduction Strategy Paper and Joint IDA/IMF Staff Assessment." World Bank Report No 37890-HT.

World Bank. 2010a. "An Evaluation of World Bank Support, 1997-2007: Water and Development." World Bank Independent Evaluation Group, Washington, DC.

World Bank. 2010b, July 1. "Water: Data and Statistics in Latin America." Retrieved at http://go.worldbank.org/ J41HSH87H0.

Wright, J., S. Gundry, and R. Conroy. 2004. "Household Drinking Water in Developing Countries: A Systematic Review of Microbiological Contamination between Source and Point-of-Use.” Tropical Medicine \& International Health 9 (1): 106-17.

Zwane, A. P., and M. Kremer. 2007. "What Works in Fighting Diarrheal Diseases in Developing Countries? A Critical Review." The World Bank Research Observer 22 (1). 